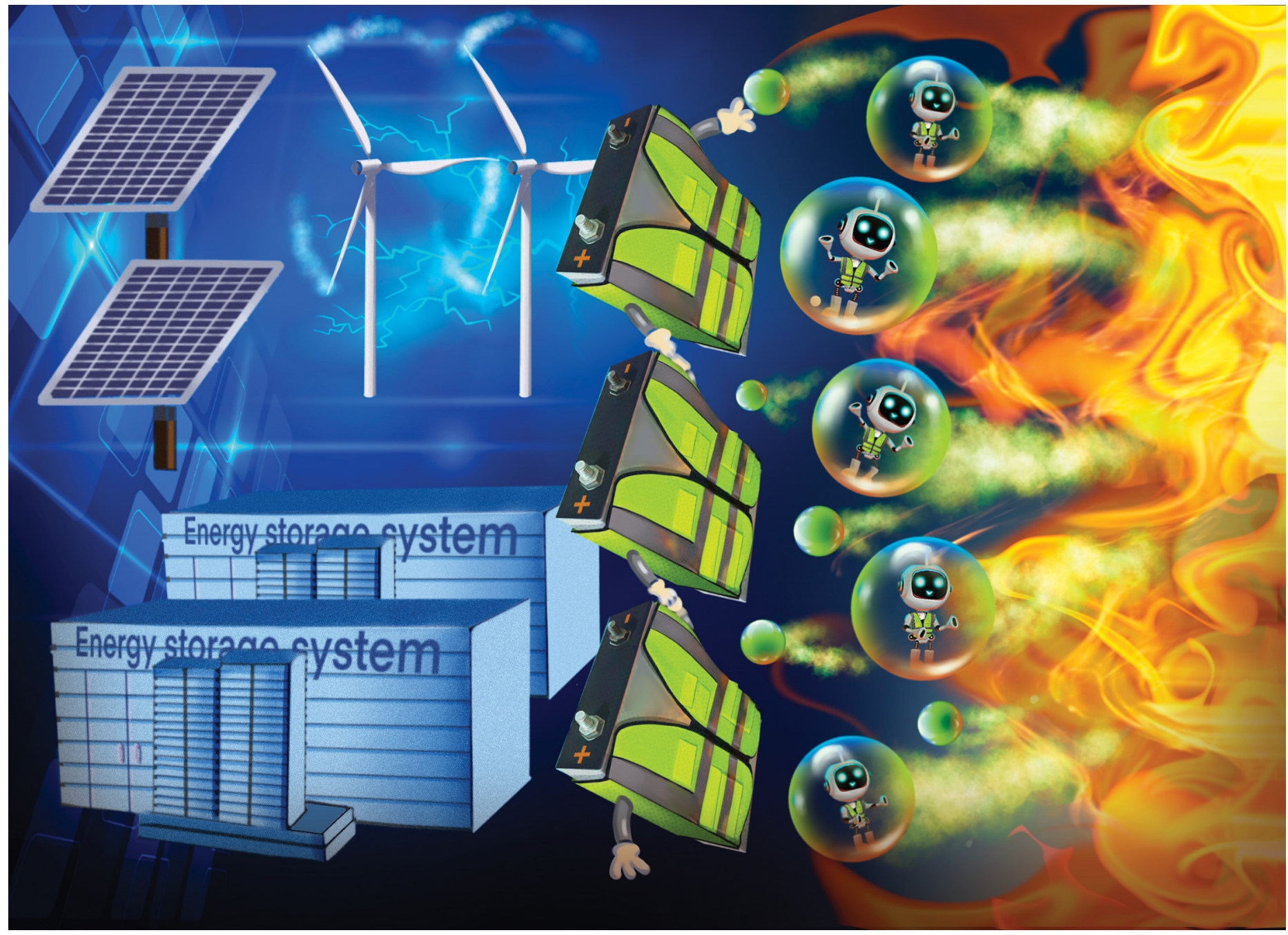

State Key Laboratory of Advanced Electromagnetic Engineering and Technology, School of Electrical and Electronic Engineering, Huazhong University of Science and Technology, Wuhan 430074, P. R. China. The research fields of Professor Yuan-Cheng Cao's group include key technologies of high safety electrochemical energy storage batteries, resource utilization of retired lithium ions batteries.

Fabrication of a microcapsule extinguishing agent with a core-shell structure for lithium-ion battery fire safety

A new safety protection mode of lithium-ion batteries was constructed by placing the fire extinguishing material in the outer layer of batteries to form a coating. The core-shell fire extinguishing agent is tuneable and can be automatically activated at the batteries in initial stage of thermal runaway, achieving the fire suppression without damaging nearby batteries. It is great beneficial to improve the safety and fire reliability of lithium-ion batteries in large-scale energy storage system.
As featured in:

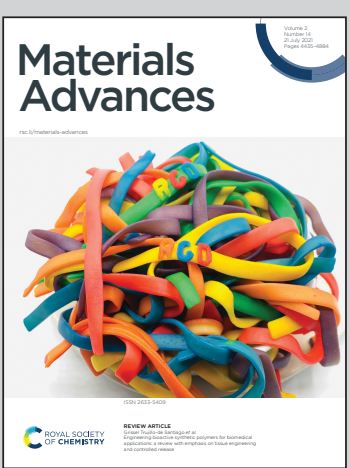

See Yuan-Cheng Cao et al., Mater. Adv., 2021, 2, 4634. 
Check for updates

Cite this: Mater. Adv., 2021, 2, 4634

Received 15th April 2021, Accepted 20th May 2021

DOI: $10.1039 / \mathrm{d} 1 \mathrm{ma} 00343 \mathrm{~g}$

rsc.li/materials-advances

\title{
Fabrication of a microcapsule extinguishing agent with a core-shell structure for lithium-ion battery fire safety $\dagger$
}

\author{
Weixin Zhang, $\ddagger^{\mathrm{a}}$ Lin Wu, $\ddagger^{\mathrm{a}}$ Jinqiao Du, ${ }^{\mathrm{b}}$ Jie Tian, ${ }^{\mathrm{b}}$ Yan $\mathrm{Li}^{\mathrm{b}}{ }^{\mathrm{C}}$ Yuming Zhao, ${ }^{\mathrm{b}} \mathrm{Hao} \mathrm{Wu},{ }^{\mathrm{c}}$ \\ Yunhui Zhong, ${ }^{\mathrm{C}}$ Yuan-Cheng Cao (D)*a and Shijie Cheng ${ }^{a}$
}

\begin{abstract}
Safety issues limit the large-scale application of lithium-ion batteries. Here, a new type of $\mathrm{N}-\mathrm{H}-$ microcapsule fire extinguishing agent with a core-shell structure is prepared by using melamine-ureaformaldehyde resin as the shell material, and perfluoro(2-methyl-3-pentanone) and heptafluorocyclopentane as the core material. Through the test of cooling and extinguishing performance, the optimal ratio of the compound extinguishing agent is $1: 1$, which can extinguish open fire in $8 \mathrm{~s}$. The microencapsulated fire extinguishing agent with a diameter of $60-80 \mu \mathrm{m}$ is pre-stored on the outer surface of the aluminum plastic film of lithium-ion batteries to form a kind of "protective clothing", and the shell material will crack and releases the wrapped fire extinguishing agent when lithium-ion batteries reach $120{ }^{\circ} \mathrm{C}$ due to thermal runaway, so as to inhibit the spread of fire, cooling from $800{ }^{\circ} \mathrm{C}$ to $30{ }^{\circ} \mathrm{C}$ in $10 \mathrm{~s}$ and inhibit the reburning of lithium-ion batteries. This work changed the liquid fire extinguishing agent into solid microcapsules, which not only proposes a new method and strategy to solve the safety problem of lithium-ion batteries, but also provides useful information for guiding the application of lithium-ion batteries.
\end{abstract}

\section{Introduction}

In recent years, lithium-ion batteries have been widely used in portable products, standby power supplies and electric vehicles due to their high energy density and long cycle life. ${ }^{1}$ However, lithium-ion batteries are inevitably faced with extrusion, puncture, temperature shock, overcharge, short circuit and other damage in the process of long-term use and storage, which will cause combustion and even explosion. ${ }^{2-4}$ Explosion accidents such as in mobile phones, electric vehicles and energy storage power stations occur from time to time, causing major equipment damage and casualties, so it is very important to solve the safety problems of large-scale applications of lithium-ion batteries. Researchers explored the specific reaction of lithium-ion battery fire including decomposition and a

\footnotetext{
${ }^{a}$ State Key Laboratory of Advanced Electromagnetic Engineering and Technology, School of Electrical and Electronic Engineering, Huazhong University of Science and Technology, Wuhan 430074, China. E-mail:yccao@hust.edu.cn

${ }^{b}$ Shenzhen Power Supply Co. Ltd., Shenzhen 518001, China

${ }^{c}$ Zhejiang Landun Electronic New Material Technology Co. Ltd., Hangzhou 311418, China

$\dagger$ Electronic supplementary information (ESI) available: Characterization of the $\mathrm{N}-\mathrm{H}$-microcapsule (SEM), and fire extinguishing performance results. See DOI: 10.1039/d1ma00343g

\$ These authors contributed equally to this work.
}

mutual reaction between SEI (solid electrolyte interphase) layers, electrolytes, anode materials and cathode materials, and a systematic theoretical analysis has been carried out in the relevant key links for solving the problem of battery safety. ${ }^{5-7}$ Adequate measures have been explore to achieve considerable 'intrinsic safety', such as improving the thermal stability of battery separators, ${ }^{8}$ optimizing the composition of the SEI layer to make batteries dendrite-free and have a longer life, ${ }^{9}$ developing flame-retardant additives to lower the flammability of liquid electrolytes ${ }^{10}$ and finding or synthesizing intrinsically nonflammable electrolytes. ${ }^{11}$ All these studies are focused on solving the early risk of thermal runaway of lithium-ion batteries, in order to prevent the combustion and explosion as much as possible, but 'complete intrinsic security' still has a long way to go. Also, the introduction of non-active substances in batteries will more or less affect the capacity, rate performance and cycle life of lithium-ion batteries..$^{12-14}$

To ensure the safety of lithium-ion batteries, an external protection mechanism can also be established. External protection can judge a fire by detecting the temperature change and voltage change of lithium-ion batteries caused by thermal runaway depending on the electronic equipment such as the temperature sensor and pressure valve, and then spray a fire extinguishing agent to put out lithium-ion battery fire. ${ }^{15}$ The introduction of fire extinguishing agents can put out the fire in time, while flame 
retardant materials only prevent the spread of the fire. ${ }^{16,17}$ Lithiumion battery fire is quite different from ordinary fire, because lithium-ion batteries are a kind of energetic material, which have the characteristics of intense combustion, rapid heat spread, strong toxicity, easy to rekindle and difficult to put out. ${ }^{18}$ The existing fire extinguishing agents, such as haloalkanes 1301, $\mathrm{CO}_{2}$ and heptafluoropropane are not suitable for lithium-ion battery fire because they can only extinguish open fire, but can't fundamentally inhibit the fire occurrence, that will cause the batteries to rekindle, and also do not have the dual functions of cooling and extinguishing. ${ }^{19-21}$ On the other hand, the fire facilities will increase the weight or volume of LiB energy storage systems, and are not absolutely reliable under the condition of thermal runaway. Therefore, the selection of an appropriate fire extinguishing agent and the design of a new type of fire extinguishing device are significant areas of research work for the large application of lithium-ion batteries. According to many research results, fluorine-containing derivative materials can block the chain reaction in the combustion process of lithium-ion batteries, and have no other impact on electrical equipment, such as perfluoro (2-methyl-3-pentanone) (Novec1230). ${ }^{22-24}$ Novec1230 is a new type of fire extinguishing agent which does not contain bromine and chlorine. The ODP (ozone depleting substance) of Novec1230 is almost zero, and will be completely degraded in the atmosphere for 1-2 weeks. ${ }^{25}$ However, Novec1230 can enhance combustion at low concentrations, so it is necessary to select a suitable fire extinguishing agent with a high boiling point, high vaporization heat and high specific heat according to the actual ignition condition of lithium-ion batteries, so as to ensure the fire extinguishing performance while taking into account the cooling ability. ${ }^{26-28}$ By mixing a fire extinguishing agent and cooling agent, a compound fire extinguishing agent for lithium-ion batteries is designed to achieve more efficient fire extinguishing technology. Among many fluorine-containing derivatives, 1,1,2,2,3,3,4-heptafluorocyclopentane (HFC) not only has the cooling effect of vaporization and endothermic contribution, but also has a great influence on specific heat. ${ }^{29,30}$ The ODP of HFC is 0 , the global warming potential is 250 , and the atmospheric lifetime is only 3.4 years according to the product introduction of Japanese ruiweng company, neither of Novec1230 or HFC will damage the ozone layer. Therefore, in order to put out the open fire of lithium-ion batteries, Novec1230 is selected as the main raw material of the special compound fire extinguishing agent, and HFC is selected as the cooling agent with strong cooling ability. Mixed Novec1230 and HFC according to a certain mass ratio can ensure the rapid extinguishing of lithium-ion batteries fire, achieve the cooling effect, and prevent lithium-ion batteries reburning.

Here we use the microcapsule technology in order to break through the traditional external protection mechanism and change the liquid fire extinguishing agent into a solid. A microcapsule is a kind of core-shell structure with a polymer as the shell material and liquid or solid as the core material, which has been widely used in many aspects. ${ }^{31-33}$ The wrapped fire extinguishing agent is released when the shell material cracks at a certain temperature, which can put out the early fire source and realize the dual effect function of flame retardants and fire extinguishing. The fire extinguishing agent is microcoated with a micron flame retardant shell to realize the micro and precise control of flame retardant materials and fire extinguishing agents in the application process. Therefore, melamine-urea-formaldehyde resin (MUF) is selected as the shell material in this work due to the low boiling point and high vapor pressure of Novec1230. MUF used as the shell material is easy to crack, and has the advantages of relatively high cross-linking density, good compactness and high mechanical strength. ${ }^{34-36}$ The addition of montmorillonite can increase the surface roughness of microcapsules and improve the stability of microcapsules. The composite fire extinguishing agent coated by microcapsules (N-H-microcapsules) is directly attached to the surface of lithium-ion batteries as a "protective clothing". The microcapsules will be destroyed when the temperature reaches a certain value, so as to release the fire extinguishing agent which can quickly block the thermal runaway process of lithium-ion batteries, and achieve the effect of lithium-ion battery cooling.

In this work, a special core-shell $\mathrm{N}-\mathrm{H}$-microcapsule was designed with Novec1230 and HFC as the compound fire extinguishing agent based on the theory of thermal runaway process of lithium-ion batteries, and a new safety protection mode of lithium-ion batteries was constructed by using microcapsule technology. The N-H-microcapsule is directly attached to the surface of lithium-ion batteries, the MUF shell of the $\mathrm{N}-\mathrm{H}$-microcapsule breaks at $120{ }^{\circ} \mathrm{C}$ when lithium-ion batteries are out of control, thus releasing Novec1230 and HFC fire extinguishing agents, so as to control the thermal runaway of lithium-ion batteries at the initial stage, cut off fire, prevent its spread, and protect the safety of the rest of the lithium-ion batteries. Through the experimental design, the optimum ratio, fire extinguishing and cooling ability of Novec1230 and HFC were verified. This work creates a new lithium-ion battery security protection strategy, provides a new way for large-scale application of lithium-ion security issues, and can be extended to the safety design of other batteries.

\section{Experimental and characterization methods}

\section{Materials}

All chemicals were commercially available and used without further purification. Two extinguishing agent candidates, perfluoro(2-methyl-3-pentanone) (Novec1230) (Shangfluoro Co., Ltd, China) and 1,1,2,2,3,3,4-heptafluorocyclopentane (HFC) (Shangfluoro Co., Ltd, China) were used as core materials, potassium heptadecafluoro-1-octanesulfonate (Shangfluoro Co., Ltd, China) as the surfactant, and polyvinyl alcohol (PVA) (degree of polymerization is 1799 , macklin, China) as the dispersing agent. To eliminate bubbles from the stirring process, 1-octanol acts as an antifoaming agent. The shell of microencapsulation was prepared by in situ polymerization of melamine (M), formaldehyde (F) solution, (37 wt $\%$ in $\mathrm{H}_{2} \mathrm{O}$, macklin, China) 
prepolymers and urea (U) (macklin, china), formaldehyde (F) solution, (37 wt \% in $\mathrm{H}_{2} \mathrm{O}$, macklin, China) prepolymers. Anhydrous sodium carbonate (macklin, China) and sulfuric acid (macklin, China) are used to adjust $\mathrm{PH}$.

\section{Synthesis of prepolymers}

$7.76 \mathrm{~g}$ of melamine, $7.40 \mathrm{~g}$ of urea, $29.98 \mathrm{~g}$ of formaldehyde solution and $30 \mathrm{~g}$ of distilled water was added into a three-mouth flask, and the $\mathrm{pH}$ was adjusted to 8.5-9.0 with anhydrous sodium carbonate. The three-mouth flask was heated from $30{ }^{\circ} \mathrm{C}$ to $70{ }^{\circ} \mathrm{C}$ at a rate of $2.5{ }^{\circ} \mathrm{C} \min ^{-1}$ in a water bath. After stirring for $1 \mathrm{~h}$, ice water was added to rapidly reduce the temperature to below $40{ }^{\circ} \mathrm{C}$. Then $375 \mathrm{~g}$ of distilled water was used to dilute the solution to obtain MUF prepolymer with a concentration of $10 \mathrm{wt} \%$.

\section{Synthesis of microcapsules}

$5 \mathrm{ml}$ Novec1230 and $5 \mathrm{ml} \mathrm{HFC}$ as core materials, $50 \mathrm{ml} 10 \mathrm{wt} \%$ MUF prepolymer as shell materials and $0.3 \mathrm{~g}$ potassium heptadecafluoro-1-octanesulfonate were mixed and stirred at $500 \mathrm{rpm}$ rotation speed for $6 \mathrm{~h}$. Then the solution was left to set for at least $6 \mathrm{~h}$ or overnight and filtrated to obtain $\mathrm{N}-\mathrm{H}$-microcapsules.

$\mathrm{N}$-Microcapsules were also synthesized in the same way as above using $10 \mathrm{ml}$ Novec1230 as the core material.

MUF without the core material was also synthesized in the same way as above but without adding extinguishing agent materials.

\section{Measurement of microcapsule hardness (HIT) and elastic modulus (EIT)}

A glass slide was cut into small squares of $1 \mathrm{~cm} \times 1 \mathrm{~cm}$ with a glass knife. A layer of glue was covered on the square glass slides evenly, and microcapsules were stuck on the small squares, then glass was fixed on the nanoindentation sample stage. The indentation displacement-load curve of the microcapsules was obtained by using Berkovich indenter with a tip radius less than

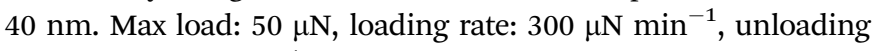
rate: $300.00 \mu \mathrm{N} \min ^{-1}$.

\section{Acute inhalation toxicity test in mice}

Static exposure, one-time limit method. In a $120 \times 100 \times 80 \mathrm{~cm}$ container, $1.92 \mathrm{~g}$ compound fire extinguishing agent sample was volatilized under the volatilizing device, resulting in an air environment of $2000 \mathrm{mg} \mathrm{m}^{-3}$ sample concentration required for the test. The test animals were placed in the container and exposed to inhalation for $4 \mathrm{H}$ at one time.

\section{Fire extinguishing test on lithium-ion battery}

The $\mathrm{LiFePO}_{4}$ and NCM523 lithium-ion soft pack batteries (40 A h) were selected as the test object, and the prepared $\mathrm{N}-\mathrm{H}$ microcapsule fire extinguishing agent powder was evenly coated on the outer surface of the aluminum plastic film in the middle of the soft pack batteries and put into the fume hood. The lithiumion batteries were ignited directly, and the effect of $\mathrm{N}-\mathrm{H}$ microencapsulated fire extinguishing agent was observed.

\section{Results and discussion}

Strategy of preparation of core-shell N-H-microcapsule and fire extinguishing method for lithium-ion batteries

Fig. 1 shows the strategy of preparation of $\mathrm{N}-\mathrm{H}$-microcapsule and application in lithium-ion battery safety design. In order to improve the safety and further promote the large-scale application of lithium-ion batteries, it is necessary to explore the safety protection technology of lithium-ion batteries. At present, the development of new flame retardant electrolytes has achieved the goal of reducing internal heat production and preventing the spread of out of control heat based on the internal safety measures. However, the internal safety measures will affect the performance and increase the difficulty of battery assembly. Conventional external safety measures such as fire-fighting devices need a series of fire-fighting supporting systems, which increase the difficulty of large-scale promotion and application of lithium-ion batteries. Here, we use microcapsule technology to encapsulate the prepared compound fire extinguishing agent and attach it to the surface of lithium-ion batteries. The $\mathrm{N}-\mathrm{H}$ microcapsule prepared in this work is a kind of core-shell structure (Fig. S1, ESI $\dagger$ ), which contains Novec1230 and HFC (Fig. S2, ESI $\dagger$ ). The N-H-microcapsule is destroyed by the runaway temperature of lithium-ion batteries to realize automatic spraying of Novec1230 and HFC, so as to quickly put out the fire and reduce the temperature of lithium-ion batteries, thus ensuring the safety of lithium-ion battery application systems. Novec1230 and HFC have the dual effects of fire extinguishing and cooling with no impact on the performance of the lithium-ion batteries, which is equivalent to wearing "protective clothing" on lithium-ion batteries. This is a new type of battery fire protection technology that can provide new fire safety protection technology and ideas to solve the problem of fire spread in the large-scale application of lithium-ion batteries.

\section{The thermal runaway reaction process of lithium-ion batteries}

It is necessary to explore the thermal runaway process of lithium-ion batteries in order to control the temperature of extinguishing agent spraying in microcapsules. The thermal runaway of lithium-ion batteries can be divided into four stages after consulting the relevant literature and exploring the experimental process in this work according to our literature research and study. ${ }^{37-39}$ As shown in Fig. 2, in the first stage between

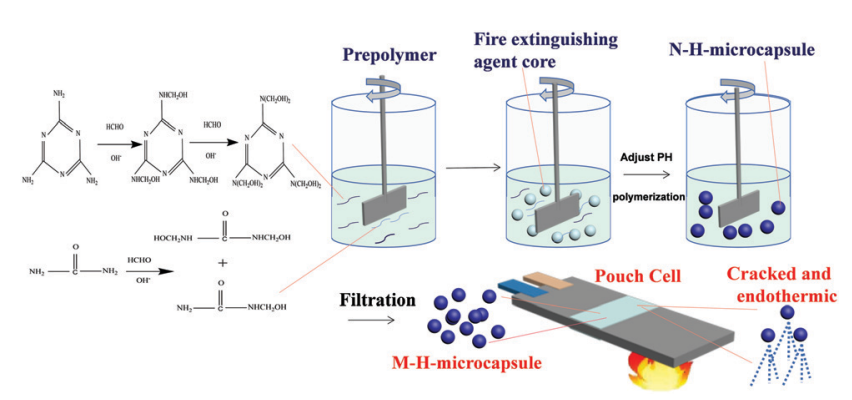

Fig. 1 Illustration of the synthesis of core-shell $\mathrm{N}-\mathrm{H}$-microcapsules and the action of the microcapsule on extinguishing lithium-ion battery fire. 


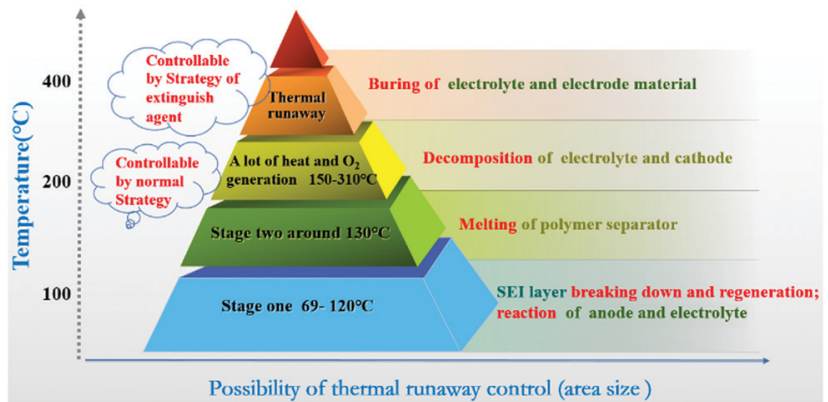

Fig. 2 Illustration the thermal runaway reaction process of lithium-ion batteries.

$69^{\circ} \mathrm{C}$ and $120{ }^{\circ} \mathrm{C}$ when thermal runaway occurs in lithium-ion batteries, SEI layers which mainly consist of stable or metastable components (such as $\mathrm{LiF}, \mathrm{Li}_{2} \mathrm{CO}_{3} \mathrm{ROCO}_{2} \mathrm{Li},\left(\mathrm{CH}_{2} \mathrm{OCO}_{2} \mathrm{Li}\right)_{2}$, and ROLi $\mathrm{Li}_{2} \mathrm{CO}_{3}$ ) break down and regenerate, lithium-ion batteries will release some combustible gas in this process. After that, the temperature of the battery will rise rapidly, and the controllability of the internal reaction will become more and more difficult. The thermal runaway of the battery will enter the second stage, the separator polyethylene (PE)/polypropylene (PP) begins to melt and the battery is prone to short-circuit when the internal temperature reaches $130{ }^{\circ} \mathrm{C}$, which further leads to the decomposition of electrolyte and cathode, and produces oxygen, that will promote the thermal runaway process of the battery and lead to a sharp rise in temperature. At this stage, the method based on an internal safety mechanism cannot restrain the thermal runaway deterioration, and only the use of a fire extinguishing agent can slow down the spread of fire, but it is generally difficult to accurately release a large amount of fire extinguishing agent in a short time. As soon as enough oxygen and heat is generated, it will be accumulated and transferred to the surrounding batteries for battery combustion, increasing the risks. Therefore, the microcapsule produced in this work needs to break down in the first stage of thermal runaway of lithium-ion batteries, so as to release fire extinguishing agent quickly, restraining the thermal runaway of lithium-ion batteries at the initial stage, and preventing the further deterioration of the thermal runaway process.

\section{Characterization of the $\mathbf{N}-\mathbf{H}-m i c r o c a p s u l e$}

The N-H-microcapsule phase change material prepared in this work by in situ polymerization is key for the encapsulation and release of the fire extinguishing agent. Therefore, it is very important to determine the morphology structure and chemical characteristics of the $\mathrm{N}-\mathrm{H}$-microcapsule. SEM, FT-TR, and EDS images are shown in Fig. 3 in order to observe the particle size and chemical structure of the prepared $\mathrm{N}-\mathrm{H}$-microcapsule. The morphology and quality of $\mathrm{N}-\mathrm{H}$-microcapsules were observed by adding different amounts of Novec1230 and HFC as core materials in the process of in situ polymerization of $\mathrm{N}-\mathrm{H}$-microcapsules to determine the amount of core materials wrapped by a MUF shell, as shown in Fig. 3A-C, optical microscopy of $\mathrm{N}-\mathrm{H}$-microcapsules with different contents of
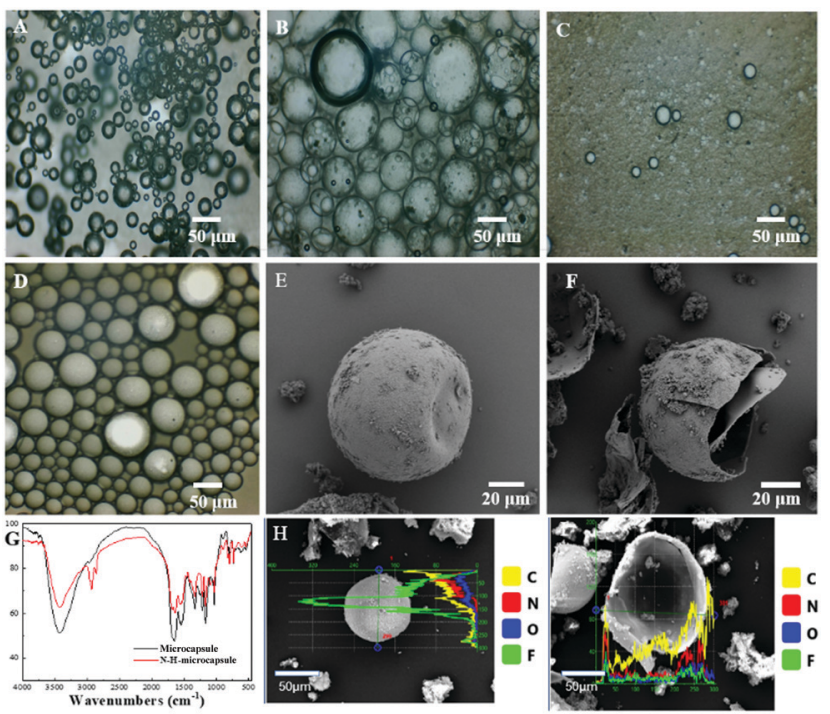

Fig. 3 Optical microscopy of $\mathrm{N}-\mathrm{H}$-microcapsules with different contents of core materials (A) $5 \mathrm{ml}$, (B) $10 \mathrm{ml}$, (C) $15 \mathrm{ml}$, and (D) $\mathrm{N}-\mathrm{H}$-microcapsule. ( $E$ and F) FE-SEM and corresponding EDS image of the $\mathrm{N}-\mathrm{H}$-microcapsule. (G) FTIR spectra of MUF and $\mathrm{N}-\mathrm{H}$-microcapsule. ( $\mathrm{H}$ and I) Cracked $\mathrm{N}-\mathrm{H}$-microcapsule decomposes due to heating.

core materials $(5 \mathrm{ml}, 10 \mathrm{ml}, 15 \mathrm{ml})$ were obtained, and it can be seen that $\mathrm{N}-\mathrm{H}$-microcapsules with $10 \mathrm{ml}$ core materials have uniform size and a high synthesis rate (Fig. 3B), while $5 \mathrm{ml}$ core materials have a small particle size and less encapsulation (Fig. 3A), and $15 \mathrm{ml}$ core materials have almost no formation due to core materials with varying-density causing sizes and shapes with different profiles (Fig. 3C). Therefore, the desired $\mathrm{N}-\mathrm{H}$-microcapsule sphere is obtained when the core material content is $10 \mathrm{ml}$. The addition of antifoaming agent prevents the reaction solution from foaming easily (Fig. S3, ESI $\dagger$ ), otherwise there will be a lot of air wrapped by the wall material, thereby reducing the yield of microcapsules. Fig. 3D shows the as prepared optical microscopy image of the $\mathrm{N}-\mathrm{H}-$-microcapsule and which size is more appropriate. To support the validation of the successful preparation of $\mathrm{N}-\mathrm{H}$-microcapsules, FT-IR spectra of the N-H-microcapsule and MUF shell are shown in Fig. 3G. The peak patterns of N-H-microcapsule and MUF shell are basically the same, in which $1564 \mathrm{~cm}^{-1}$ corresponds to the $\mathrm{C}=\mathrm{O}$ characteristic absorption peak of the MUF shell, ${ }^{40}$ $1494 \mathrm{~cm}^{-1}$ and $814 \mathrm{~cm}^{-1}$ belong to the triazine ring of Novec1230 and HFC. ${ }^{41,42}$ SEM images of the N-H-microcapsule (Fig. 3E and F) further reveal the detailed core-shell structure. Fig. 2C shows that the $\mathrm{N}-\mathrm{H}$-microcapsule presents an appearance of a single sphere with an average diameter of about $80 \mu \mathrm{m}$, and the particle size of the N-H-microcapsule is between $60-100 \mu \mathrm{m}$ (Fig. S4, ESI†). The SEM image in Fig. 2E shows the $\mathrm{N}-\mathrm{H}$-microcapsule after releasing the fire extinguishing agent core material by heating to obtain a cracked structure. Fig. $3 \mathrm{H}$ and I display elemental analysis of Fig. 3E and F. The C, $\mathrm{N}$ and $\mathrm{O}$ elementals in Fig. $3 \mathrm{H}$ are evenly distributed throughout the $\mathrm{N}-\mathrm{H}$-microcapsule except for elemental $\mathrm{F}$ which is concentrated in the middle of the $\mathrm{N}-\mathrm{H}$-microcapsule sphere, proving that the Novec1230 and HFC core materials are 
wrapped inside the microcapsule. The cracked N-H-microcapsule in Fig. 3I presents a relatively low and uniform $\mathrm{F}$ content, and the results show that the Novec1230 and HFC fire extinguishing agent were released after the $\mathrm{N}-\mathrm{H}$-microcapsule was broken, which is also illustrated by the elemental analysis of $\mathrm{N}-\mathrm{H}$-microcapsules and cracked $\mathrm{N}-\mathrm{H}$-microcapsule (the weight percent of the $\mathrm{F}$ element decreased from 47.27 to 9.09, Table S1, ESI $\dagger$ ). These results in Fig. 2 fully show that the core-shell structure $\mathrm{N}-\mathrm{H}$-microcapsules designed in this work are successfully prepared.

Allowing overheating of the core material to a temperature higher than its boiling point (under normal conditions) is the distinguishing feature and difficulty of this work. The release of the core material of the fire extinguishing agent in the $\mathrm{N}-\mathrm{H}$ microcapsules is not only related to the type of core material, but to the strength and elastic modulus of the shell material. In order to explore the comprehensive relationship between release temperature and core-shell material, in situ imaging nanoindentation was used to characterize the differences in the modulus of elasticity and hardness. Fig. 4 presents the nanoindentation displacement-load curves of N-microcapsule and $\mathrm{N}-\mathrm{H}$-microcapsule, and their image in the process from pressure applying to the breaking process. From Fig. 4A and B, it is concluded that the hardness (HIT) of N-microcapsule and $\mathrm{N}-\mathrm{H}$-microcapsule are 24.595 and 139.097 , this can probably infer that the former is easier to break than the latter, and the vapor pressure inside the microcapsule rises when the temperature rises. The elasticity modulus EIT of the N-microcapsule and $\mathrm{N}-\mathrm{H}$-microcapsule are 24.595 and 139.097 , which indicates that the rupture process of the former microcapsules is faster than the latter. Increasing the load until the microcapsules rupture, the pressures at the time point of just rupture are $0.47 \mathrm{mN}$ and $4.1 \mathrm{mN}$ (Fig. 3E and 4D). This also confirms the relationship between the difficulty of fracture and the HIT of the microcapsule. The above microcapsule was also chosen for thermal analysis by thermogravimetric analysis (TGA) and differential scanning calorimetry (DSC) under an Ar atmosphere in order to find out the actual release process of the fire extinguishing agent in the microcapsule. DSC test results of N-microcapsule
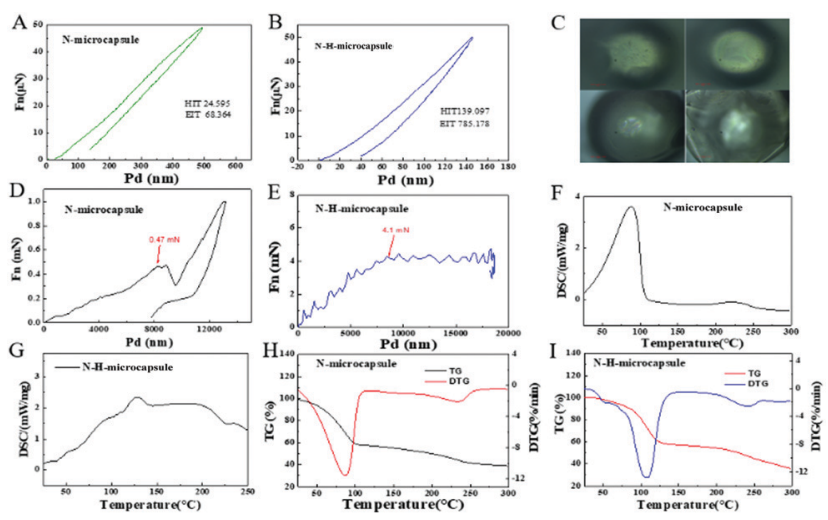

Fig. 4 Nanoindentation curves of ( $A$ and $B$ ) N-microcapsule and ( $D$ and $E$ ) $\mathrm{N}-\mathrm{H}$-microcapsule. (C) Microscope photo of their crushing process. ( $F$ and $H$ ) DSC and TG curve of $\mathrm{N}$-microcapsule and ( $\mathrm{G}$ and $\mathrm{I}$ ) $\mathrm{N}-\mathrm{H}$ microcapsule. and $\mathrm{N}-\mathrm{H}$-microcapsule show that the $\mathrm{N}$-microcapsules start to absorb heat from $45{ }^{\circ} \mathrm{C}$ to $110{ }^{\circ} \mathrm{C}$ (Fig. 4F) and the degree of reach to the endothermic peak at $88.3{ }^{\circ} \mathrm{C}$, while $\mathrm{N}-\mathrm{H}$ microcapsules starting from $50{ }^{\circ} \mathrm{C}$ to $150{ }^{\circ} \mathrm{C}$ reach the endothermic peak at $128.9{ }^{\circ} \mathrm{C}$ (Fig. 4G). The endothermic process of $\mathrm{N}$-H-microcapsule is sustainable but slower than the endothermic process of $\mathrm{N}$-microcapsule due to the bigger elastic modulus of the $\mathrm{N}-\mathrm{H}$-microcapsule and physical properties of the fire extinguishing agent in the microcapsule. TG analysis can be observed from Fig. $4 \mathrm{H}$ and I, the N-microcapsule shows the quick weight loss is $41.96 \mathrm{wt} \%$ within the temperature range of $40{ }^{\circ} \mathrm{C}$ to $125{ }^{\circ} \mathrm{C}$, and the slow weight loss is $18.26 \mathrm{wt} \%$ from $125{ }^{\circ} \mathrm{C}$ to $300{ }^{\circ} \mathrm{C}$. As for the $\mathrm{N}-\mathrm{H}$-microcapsule, the weight loss is $43.12 \mathrm{wt} \%$, within the temperature range of $45{ }^{\circ} \mathrm{C}$ to $160{ }^{\circ} \mathrm{C}$, and the mass loss is $21.41 \mathrm{wt} \%$ from $160{ }^{\circ} \mathrm{C}$ to $300{ }^{\circ} \mathrm{C}$. Their mass loss peak is at the position of $88{ }^{\circ} \mathrm{C}$ and 128.9 respectively. Quick weight loss from $125{ }^{\circ} \mathrm{C}$ to $300{ }^{\circ} \mathrm{C}$ indicates that the $\mathrm{N}-\mathrm{H}$-microcapsule has a longer release temperature range.

\section{Fire extinguishing performance}

In order to determine the optimal composite ratio of Novec1230 and HFC in the compound fire extinguishing agent, and test their actual fire extinguishing ability and cooling effect, here we built a model that can test the cooling ability of Novec1230 and HFC (as shown in Fig. 5 and Fig. S5, ESI $\dagger$ ). The heating plate is placed in the middle of the stainless steel pan, a layer of insulating ceramic gasket is placed between the pan and the heating plate in the device model, and a $32650\left(\mathrm{LiFePO}_{4}\right)$ lithium-ion battery was selected as the test sample. The heating plate was heated to $300{ }^{\circ} \mathrm{C}$ and then stopped heating, and the fire extinguishing agent was sprayed for $40 \mathrm{~s}$. The temperature curve with time was obtained from the temperature data collected by the thermocouple. $T_{1}$ and $T_{2}$ represent the temperature of two batteries advanced to the thermal runaway battery, the temperature curve obtained is shown in Fig. 5B through the

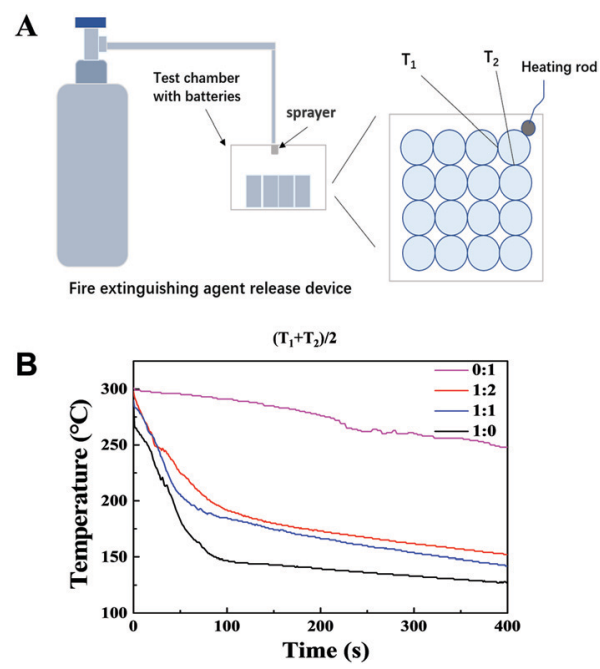

Fig. 5 (A) Device and schematic diagram of extinguishing agent test (HFC: Novec1230 = 1:2, 1:0,1:1,0:1). (B) Temperature vs time curve of $\left(T_{1}+T_{2}\right) / 2$ test in $A$. 
cooling test of HFC and Novec1230 with different composite proportions. There was a steep cooling trend in the first $40 \mathrm{~s}$ curve in the temperature curve, which represents the rapid cooling process of the heating plate when the fire extinguishing agent begins to spray in the first stage. For the fire extinguishing agents with low boiling point, such as Novec1230, the cooling effect is mainly due to the contribution of vaporization and heat absorption, while the boiling point of HFC is relatively high, so in addition to the contribution of vaporization and heat absorption, the specific heat effect is also relatively large. The temperature drop rate of Novec1230 becomes extremely slow after $40 \mathrm{~s}$, which means that the fire extinguishing agent is consumed after spraying, and there is no heat absorption effect, so the subsequent temperature drop of the heating plate mainly comes from the natural heat exchange with the outside world. However, the temperature of the extinguishing agent containing HFC still had a relatively fast rate of decline after the fire extinguishing agent was completely sprayed, which indicates that HFC was not completely vaporized and there is a surplus to continue to consume heat absorption until about $400 \mathrm{~s}$ before the decline trend slows down. It can be seen that when the ratio of HFC/ Novec1230 is $1: 1$, the cooling effect is obviously better than that of the Novec1230 and HFC/Novec1230 ratio of $1: 2$ from the cooling curve. Although the pure HFC has the best cooling effect according to the cooling ability test, it needs to be considered that the fire extinguishing agent must have the dual functions of fire extinguishing and cooling, so it is necessary to verify the fire extinguishing performance of the Novec1230 and HFC/Novec1230 ratio of $1: 1$.

In order to further verify the fire extinguishing ability of Novec1230 and HFC, we compared and tested the fire extinguishing ability of Novec1230 and HFC/Novec1230 with a ratio of $1: 1$. The inflammables can be ignited in the experimental cabinet, and the fire extinguishing agent can be sprayed after burning for $30 \mathrm{~s}$, and the time required for the open fire to go out was recorded. Through the contrast test, it is found that the Novec1230 can extinguish the open fire within $15 \mathrm{~s}$ after the fire extinguishing agent is sprayed, and the open fire can be extinguished within $8 \mathrm{~s}$ after HFC/Novec1230 with the ratio of $1: 1$ is sprayed. We further tested the extinguishing ability of HFC/Novec1230 with the ratio of 1:1 fire extinguishing agent for lithium-ion battery fire under real life conditions. As shown in Fig. 6A-D, the superheated heat runaway is simulated by heating the heating rod. Six 32650 batteries $(23.12 \mathrm{~W} \mathrm{~h} \times 3.6 \mathrm{~V})$ in the explosion-proof box were ignited, and $500 \mathrm{~g}$ fire extinguishing agent was sprayed gradually after the batteries were on fire. It can be seen that the fire was put out successfully after spraying the fire extinguishing agent for $10 \mathrm{~s}$. The fire extinguishing agent was sprayed for $20 \mathrm{~s}$ continuously to cool the batteries, the reaction inside the batteries stopped gradually, the surface temperature and internal temperature of the batteries were reduced to room temperature, and the batteries had no reburning. These results show that this HFC/ Novec1230 with the ratio of $1: 1$ compound fire extinguishing agent is effective for extinguishing lithium-ion battery fires and achieving a cooling effect. The thermal decomposition
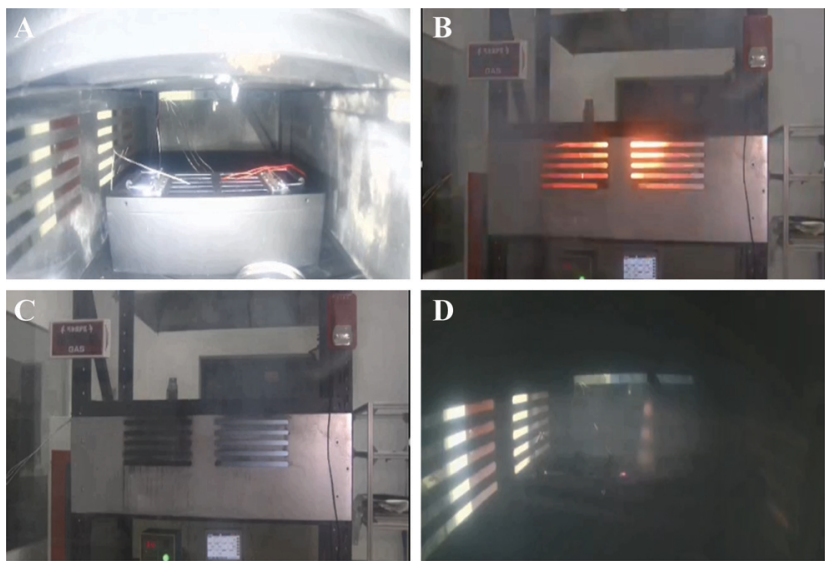

Fig. 6 Test chart of fire extinguishing capacity of (A) $32650 \mathrm{LiFePO}_{4}$ batteries module (including module shell) in fire extinguishing experiment. (B) Thermal runaway fire of lithium-ion batteries module. (C) Extinguishing an open fire after spraying the extinguishing agent. (D) There is no reburning of the thermal runaway lithium-ion battery module.

products of Novec1230 and HFC (mainly HF) are within the range acceptable to the human body during firefighting. In order to further investigate the toxicity of the compound fire extinguishing agent, the Beijing ZKGX institute of chemical technology (Animal Lab) was entrusted to carry out acute inhalation toxicity test in mice (the test method is shown on Page 3 in the revised manuscript). The results showed that there was no death after the mice inhaled the sample for a short time $(4 \mathrm{~h})$. It was inferred that the acute inhalation was $\mathrm{LC}_{50}>$ $2000 \mathrm{mg} \mathrm{m}^{-3}$. According to the acute toxicity classification standard (GB/T 21605-2008), the acute inhalation toxicity of the compound fire extinguishing agent is low.

At first, the prepared $\mathrm{N}-\mathrm{H}$-microcapsule powder was attached to the glass slide to verify the fire extinguishing performance of the $\mathrm{N}-\mathrm{H}$-microcapsule and the fire extinguishing effect on lithium-ion batteries $\left(\mathrm{LiFePO}_{4}\right.$ lithium ion soft pack battery, $3.2 \mathrm{~V}, 40 \mathrm{~A} \mathrm{~h}$ ). It can be seen that the alcohol lamp quickly and automatically goes out in about $10 \mathrm{~s}$ after lighting the alcohol lamp (Fig. 7A and B), which directly indicates that the $\mathrm{N}-\mathrm{H}$-microcapsule will crack when heated and release Novecs1230 and HFC to put out the alcohol lamp. A smallscale fire extinguishing test was conducted to confirm the fire extinguishing performance of the $\mathrm{N}-\mathrm{H}$-microcapsule, as shown in Fig. 7C-F. The N-H-microcapsule powder was evenly attached to the outer surface of the aluminum plastic film. The ignition of lithium-ion batteries with $\mathrm{N}-\mathrm{H}$-microcapsules is used to simulate the combustion phenomenon of the battery due to the runaway heat. After the lithium-ion battery was ignited, it was found that the fire began to spread rapidly, but decreased rapidly when the fire reached the part covered by the $\mathrm{N}-\mathrm{H}$ microcapsule, the open flame was completely extinguished after $10 \mathrm{~s}$ and the surface temperature of the battery dropped to room temperature. This is because the $\mathrm{N}-\mathrm{H}$-microcapsule was destroyed with the increase of temperature, and Novec1230 and HFC were released, which can quickly put out the lithiumion battery fire. Further observation showed that the battery had 


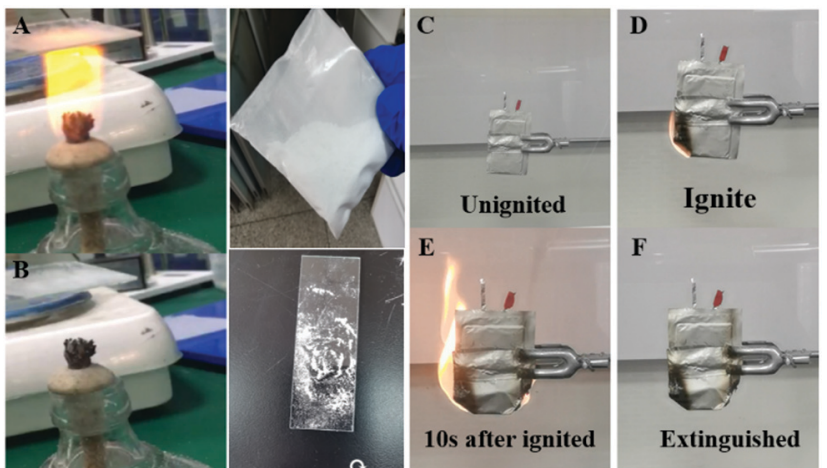

Fig. 7 Fire extinguishing effect of $\mathrm{N}-\mathrm{H}$-microcupsule ( $\mathrm{A}$ and $\mathrm{B}$ ) attached to a glass slide. (C-F) Action on a pouch cell wrapped in a plastic film.

no reburning, which indicated that the $\mathrm{N}-\mathrm{H}$-microcapsule fire extinguishing agent in this work had the ability to quickly extinguish the open fire of lithium-ion batteries, and the temperature of the lithium-ion batteries could decrease from $800{ }^{\circ} \mathrm{C}$ to $30^{\circ} \mathrm{C}$ within $15 \mathrm{~s}$. As shown in Table S1 (ESI $\dagger$ ), the minimum amount of $\mathrm{N}-\mathrm{H}$ microcapsule required to achieve the best fire extinguishing performance in lithium-ion batteries was determined to be $5 \mathrm{~g}$ after testing the fire extinguishing performance of the lithium-ion battery loaded with different quality $\mathrm{N}-\mathrm{H}$ microcapsules. The test results show that the ignition and explosion of an NCM235 battery $(4.2 \mathrm{~V}, 40 \mathrm{~A} \mathrm{~h})$ is more intense, as shown in Fig. S6 (ESI $\dagger$ ) in the comparison test diagram. Therefore, the use of the $\mathrm{N}-\mathrm{H}$-microcapsule prepared in this work can also extinguish the NCM523 battery fire caused by uncontrolled heat, but more microcapsules are needed. The minimum amount of $\mathrm{N}-\mathrm{H}$ microcapsule required to achieve the best fire extinguishing performance in NCM523 batteries is $15 \mathrm{~g}$. In order to further confirm that Novec1230 and HFC are not corrosive towards the outer packaging material of the soft-pack battery, the soft pack battery was immersed in the compound extinguishing agent, and no damage was found on the surface of the soft pack battery after 7 days of observation.

\section{Conclusion}

In order to improve the safety of the large-scale application of lithium-ion batteries, a core-shell $\mathrm{N}-\mathrm{H}$-microcapsule fire extinguishing agent was prepared by using microcapsule technology with a low melting point composite polymer MUF as the shell material and Novec1230 and HFC compound fire extinguishing agents as the core. Through a direct fire extinguishing test and thermal runaway test of lithium-ion battery modules, the fire extinguishing ability and cooling ability of the compound fire extinguishing agent are maximized when the ratio of Novec1230 and HFC is $1: 1$. According to the concept of lithium-ion battery "protective clothing", the $\mathrm{N}-\mathrm{H}$ microcapsule fire extinguishing agent is attached to the outer surface of the aluminum plastic film of lithium-ion batteries, which not only effectively extinguishes lithium-ion battery fire, but also quickly reduces the battery temperature, achieve the cooling range from $800{ }^{\circ} \mathrm{C}$ to $30{ }^{\circ} \mathrm{C}$ within $15 \mathrm{~s}$, and effectively inhibits the secondary or multiple reburning of lithium-ion battery fire. The concept of the compound fire extinguishing agent and "protective clothing" prepared in this work is a new fire safety technology for solving the safety problem of lithium-ion batteries, and providing a safety guarantee for the large-scale application of lithium-ion batteries.

\section{Conflicts of interest}

There are no conflicts to declare.

\section{Acknowledgements}

W. Z., L. W. and Y.-C. C. conceived and designed the experiments, and co-wrote the paper. L. W. and W. Z. performed most of the experiments. J. D., J. T., Y. L., and Y. Z. participated in the discussions and synthesis. H. W. and Y. Z. participated in the fire extinguishing test. All authors discussed the results and commented on the manuscript. This project was supported by funding from the National Natural Science Foundation of China (52077096) and the China Southern Power research fund for fire safety for large scale grid energy storage system (090000KK52190179).

\section{Notes and references}

1 H. Chen, Y. Fang, X. Liu, X. Jiang, F. Zhong, H. Yang, X. Ai and Y. Cao, A controllable thermal-sensitivity separator with an organic-inorganic hybrid interlayer for high-safety lithium-ion batteries, Mater. Chem. Front., 2021, 5, 2313-2319.

2 X. Head, Y. Yang, M. Cristianc, J. Wang, X. Hou, B. Yan, J. Li, T. Zhang, E. Paillard, M. Swietoslawskid, R. Kosteckid, M. Wintera and J. Li, Uniform lithium electrodeposition for stable lithium-metal batteries, Nano Energy, 2020, 67, 104172.

3 M. Zhao, The pursuit for practical lithium-sulfur batteries, Chem, 2020, 6, 3161-3162.

4 L. Zhang, X. Zhang, G. Tian, Q. Zhang, M. Knapp, H. Ehrenberg, G. Chen, Z. Shen, G. Yang, L. Gu and F. Du, Lithium lanthanum titanate perovskite as an anode for lithium ion batteries, Nat. Commun., 2019, 11, 1-8.

5 F. Wu and Y. Yu, Guidelines and trends for next-generation rechargeable lithium and lithium-ion batteries, Chem. Soc. Rev., 2020, 49, 1569-1614.

6 X. Li, J. Liang, X. Yang, K. R. Adair, C. Wang, F. Zhao and $\mathrm{X}$. Sun, Progress and perspectives on halide lithium conductors for all-solid-state lithium batteries, Energy Environ. Sci., 2020, 13, 1429-1461.

7 N. Angulakshmi, R. B. Dhanalakshmi, M. Kathiresan, Y. Zhou and A. M. Stephan, The suppression of lithium dendrites by a triazine-based porous organic polymer-laden PEO-based electrolyte and its application for all-solid-state lithium batteries, Mater. Chem. Front., 2020, 4, 933-940. 
8 X. Huang, R. He, M. Li, M. Chee, P. Dong and J. Lu, Functionalized separator for next-generation batteries, Mater. Today, 2020, 41, 143-155.

9 H. Wang, D. Zhai and F. Kang, Solid electrolyte interphase (SEI) in potassium ion batteries, Energy Environ. Sci., 2020, 13, 4583-4608.

10 J. Li, L. Zhang, F. R. Qin, B. Hong, Q. Xiang, K. Zhang, J. Fang and Y. Q. Lai, $\mathrm{ZrO}\left(\mathrm{NO}_{3}\right)_{2}$ as a functional additive to suppress the diffusion of polysulfides in lithium-sulfur batteries, J. Power Sources, 2019, 442, 227232.

11 X. Zhou, H. Jiang, H. Zheng, Y. Sun, X. Liang and H. Xiang, Nonflammable hybrid solid electrolyte membrane for a solid-state lithium battery compatible with conventional porous electrodes, J. Membr. Sci., 2020, 603, 117820.

12 Y. F. Dong, B. L. Wang, K. N. Zhao, Y. H. Yu, X. D. Wang and L. Q. Mai, et al., Air-stable porous $\mathrm{Fe}_{2} \mathrm{~N}$ encapsulated in carbon microboxes with high volumetric lithium storage capacity and a long cycle life, Nano Lett., 2017, 17, 5740-5746.

13 M. S. Balogun, M. H. Yu, Y. C. Huang, C. Li, P. P. Fang and Y. Liu, et al., Binder-free $\mathrm{Fe}_{2} \mathrm{~N}$ nanoparticles on carbon textile with high power density as novel anode for highperformance flexible lithium ion batteries, Nano Energy, 2015, 11, 348-355.

14 R. Ding, J. Zhang, J. Zhang, Z. Li, C. Wang and M. Chen, Core-shell Fe2N@amorphous carbon nanocomposite-filled 3D graphene framework: an additive-free anode material for lithium-ion batteries, Chem. Eng. J., 2019, 360, 1063-1070.

15 Z. Liao, S. Zhang, K. Li, G. Zhang and T. G. Habetler, A survey of methods for monitoring and detecting thermal runaway of lithium-ion batteries, J. Power Sources, 2019, 436, 226879.

16 S. Twadell, Web exclusive. annals graphic medicine - fire extinguishers, Ann. Intern. Med., 2020, 173, W59-W63.

17 Y. Liu, X. Wang, T. Liu, J. Ma, G. Li and Z. Zhao, Preliminary study on extinguishing shielded fire with water mist, Process Saf. Environ. Prot., 2020, 141, 344-354.

$18 \mathrm{M}$. Li, J. Lu, Z. W. Chen and K. Amine, 30 years of lithiumion batteries, Adv. Mater., 2018, 30, 1800561.

19 J. Wang, Y. Yamada, K. Sodeyama, E. Watanabe, K. Takada, Y. Tateyama and A. Yamad, Fire-extinguishing organic electrolytes for safe batteries, Nat. Energy, 2018, 3, 22-29.

20 L. Zhang, Y. Li, Q. Duan, M. Chen, J. Xu, C. Zhao, J. Sun and Q. Wang, Experimental study on the synergistic effect of gas extinguishing agents and water mist on suppressing lithium-ion battery fires, J. Energy Storage, 2020, 32, 101801.

21 P. Sun, R. Bisschop, H. Niu and X. Huang, A Review of Battery Fires in Electric Vehicles, Fire Technol., 2020, 56, 1361-1410.

22 L. Jiang, Q. Wang and J. Sun, Electrochemical performance and thermal stability analysis of $\mathrm{LiNi}_{x} \mathrm{Co}_{y} \mathrm{Mn}_{z} \mathrm{O}_{2}$ cathode based on a composite safety electrolyte, J. Hazard. Mater., 2018, 351, 260-269.

23 L. Jiang, Q. Wang, K. Li, P. Ping, L. Jiang and J. Sun, A selfcooling and flame-retardant electrolyte for safer lithium ion batteries, Sustain, Energy Fuels, 2018, 2, 1323-1331.
24 R. Sierra, Comment on "atmospheric degradation of perfluoro-2-methyl-3-pentanone: photolysis, hydrolysis, and hydration", Environ. Sci. Technol., 2013, 47, 4953-4958.

25 D. Jackson, C. Young and M. Hurley, Atmospheric degradation of pemuoro-2-methyl-3-pentanone: photolysis, hydrolysis and hydratio, Environ. Sci. Technol., 2011, 19, 8030-8036.

26 B. D. Ditch, P. E. Rivers and S. Thomas, ThermaI decomposition products testing with C6F-ketone, Halon Options Technical Working Conference, 2001, vol 349, pp. 24-26.

27 J. Pagliaro, G. Linteris and P. Sunderland, Combustion inhibition and enhancement of premixed methane-air names by halon replacemenIs, Combust. Flame, 2015, 162, 41-49.

28 V. Babushok, G. Linteris and O. Meier, Combustion properties of halogenaed fire suppressants, Combust. Flame, 2015, 159, 3569-3575.

29 W. Chen, J. He, Y. Jiang, H. Zhang and X. Zhou, Experimental and theoretical studies on the atmospheric degradation of 1,1,2,2,3,3,4-heptafluorocyclopentane, Atmos. Environ., 2019, 196, 38-43.

30 X. Zhou, D. Lu, M. Chao and W. Chen, Experimental and theoretical studies on the thermal decomposition of 1,1,2,2,3,3,4-heptafluorocyclopentane, J. Fluorine Chem., 2014, 164, 70-77.

31 L. Abdolmaleki, S. M. Sadrameli and A. Pirvaram, Application of environmental friendly and eutectic phase change materials for the efficiency enhancement of household freezers, Renewable Energy, 2020, 145, 233-241.

32 J. Cui, X. Q. Li, Z. Q. Pei and Y. Pei, A long-term stable and environmental friendly self-healing coating with polyaniline/sodium alginate microcapsule structure for corrosion protection of water-delivery pipelines, Chem. Eng. J., 2019, 358, 379-388.

33 A. Seongpil, M. W. Lee, A. L. Yarin and S. S. Yoon, A review on corrosion-protective extrinsic self-healing: comparison of microcapsule-based systems and those based on coreshell vascular networks, Chem. Eng. J., 2018, 344, 206-220.

34 V. Sebastian, A. Andreea, C. Andreia, M. Cristian and V. Stefan, The synthetization and analysis of dicyclopentadiene and ethylidene-norbornene microcapsule systems, Polymers, 2020, 12, 1053-1061.

35 S. Han, S. Lyu, Z. Chen, S. Wang and F. Fu, Fabrication of melamine-urea-formaldehyde/paraffin microcapsules modified with cellulose nanocrystals via in situ polymerization, J. Mater. Sci., 2019, 54, 7383-7396.

36 X. Wang, C. Zhang, K. Wang, Y. Huang and Z. Chen, Highly efficient photothermal conversion capric acid phase change microcapsule: silicon carbide modified melamine urea formaldehyde, J. Colloid Interface Sci., 2021, 582, 30-40.

37 N. Galushkin, N. Yazvinskaya and D. Galushkin, Study of thermal runaway electrochemical reactions in alkaline batteries, J. Electrochem. Soc., 2015, 162, 2044-2050.

38 X. Feng, D. Ren, X. He and M. Ouyang, Mitigating thermal runaway of lithium-Ion batteries, Joule, 2020, 4, 743-770.

39 M. Chen, Q. Sun, K. Wu, B. Liu, P. Peng and Q. Wang, A thermal runaway simulation on a lithium yitanate battery and the battery module, Energies, 2015, 8, 490-500. 
40 S. Han, S. Lyu, Z. Chen, F. Fu and S. Wang, Combined stabilizers prepared from cellulose nanocrystals and styrene-maleic anhydride to microencapsulate phase change materials, Carbohydr. Polym., 2020, 234, 115923.

41 D. Jackson, C. Young and M. Hurley, Atmospheric Degradation of Perfluoro-2-methyl-3-pentanone: Photolysis,
Hydrolysis and Hydration, Environ. Sci. Technol., 2011, 45, 8030-8036.

42 S. M. Kang, X. Zhang and D. R. MacFarlane, High nitrogen gas solubility and physicochemical properties of [C4mpyr] [eFAP]-fluorinated solvent mixtures, J. Phys. Chem. C, 2019, 123, 21376-21385. 